\title{
Evidence that the photoperiod controls the annual changes in testosterone secretion, testicular and body weight in subtropical male goats
}

\author{
José Alberto Delgadillo ${ }^{\mathrm{a} *}$, María Elena CoRTEZ ${ }^{\mathrm{a}}$, Gerardo DuARTE ${ }^{\mathrm{a}}$, \\ Philippe CHEMINEAU ${ }^{\mathrm{b}}$, Benoît MALPAUX ${ }^{\mathrm{b}}$ \\ a Centro de Investigación en Reproducción Caprina, Universidad Autónoma Agraria Antonio Narro, \\ Periférico y Carretera a Santa Fe, A.P. 940, Torreón, Coahuila, México \\ b Physiologie de la Reproduction et des Comportements, UMR 6073 INRA-CNRS-Université de Tours, \\ 37380 Nouzilly, France
}

(Received 23 June 2003; accepted 5 February 2004)

\begin{abstract}
The aim of this study was to determine whether the reproductive seasonality of local male goats from subtropical Mexico $\left(26^{\circ} \mathrm{N}\right)$ is controlled by photoperiod. The control group $(n=7)$ remained in an open shed under natural daylight. The two experimental groups ( $n=6$ each) were placed in light-proof buildings and exposed for 2 years (yr) to alternations of 3 months (mo) of long days and 3 mo of short days. One group was first exposed to long days and the other one to short days. Body and testicular weights were determined every $2 \mathrm{wk}$. Blood samples were obtained weekly to determine testosterone plasma concentrations. In the control group, the body weight exhibited variations $(P<0.0001)$ and it increased during the non-breeding season. In both treated groups, long days stimulated weight gain and short days inhibited it $(P<0.0001)$. In the control group, testicular weight displayed variations $(P<0.0001)$, and high values were registered in June. In the treated groups, a testicular weight reduction occurred 6-9 mo after the onset of the study. Afterwards, the changes in testicular size varied according to daylength $(P<0.01)$. The pattern of plasma testosterone concentration in the control group varied over the study $(P<0.0001)$ and the levels were higher from May-June to November. In both treated groups, the changes in testosterone secretion occurred according to photoperiod changes $(P<0.0001)$. Short days enhanced testosterone secretion one photoperiodic cycle after the onset of the study and long days inhibited it. Local male goats from subtropical Mexico are sensitive to photoperiodic changes and this environmental cue may control the timing of the breeding season in natural conditions.
\end{abstract}

male goats / testicular weight / testosterone / photoperiod / subtropics

\section{INTRODUCTION}

Many breeds of sheep and goats originated or adapted to subtropical latitudes exhibit seasonal variations of their sexual activity $[1,2]$. In these latitudes, it is often thought that nutrition is the limiting factor of reproductive activity and that food availability controls the timing of the annual reproductive season [3, 4]. For instance, in Australian cashmere goats raised in subtropical latitudes, endocrine activity, sexual

* Corresponding author: joaldesa@yahoo.com 
behaviour and gonadal activity are dramatically influenced by nutritional levels [3]. The sexual season begins earlier in wellnourished than in undernourished males. In subtropical Mexico, most goats graze on native pasture without supplementary feeding and large seasonal variations in food availability are encountered. In this environment, the season of sexual quiescence in males and anoestrus in females coincides with the dry season, thus it is often thought that nutrition is responsible for reproductive seasonality [5]. However, the seasonality of sexual activity is also observed when these animals are well-nourished at a constant level [6], which suggests that food availability is not the main environmental factor responsible for seasonality in this subtropical environment. In males, the breeding season, characterised by an increased testicular size and a high quantitative and qualitative sperm production, lasts from March to October. Testosterone secretion, and consequently sexual behaviour, also vary dramatically throughout the year but the timing of these changes is different from that of spermatogenesis: testosterone secretion increases abruptly in May and remains elevated until November [6]. The year-toyear repeatability in the onset of reproductive activity suggests that a very reliable environmental factor, such as photoperiod, may be used by these animals to time their sexual activity, in a similar way as species generally do in temperate latitudes. Recently we demonstrated that the association of long days followed by melatonin or natural short days stimulates the growth of the testis, testosterone secretion, sperm production and an intense sexual activity of Mexican local males during the rest season [7-9], as reported in males of temperate breeds $[10,11]$. In the present study, we tested the hypothesis that these animals are responsive to variations in photoperiod observed in northern Mexico, which would suggest that photoperiod can control the annual reproductive cycle of male goats in this subtropical latitude.

\section{MATERIALS AND METHODS}

\subsection{General}

The study was performed in Torreón (latitude $26^{\circ} 23^{\prime} \mathrm{N}$, longitude $104^{\circ} 47^{\prime} \mathrm{W}$ ), the State of Coahuila, Mexico. Photoperiod in this region varies from 13 hours (h) 41 minutes ( $\mathrm{min}$ ) of light at the summer solstice to $10 \mathrm{~h} 19 \mathrm{~min}$ of light at the winter solstice. The area is characterised by a dry climate with an average annual rainfall of $266 \mathrm{~mm}$ (range: 163 to $504 \mathrm{~mm}$ ) generally occurring from June to September with a wide interyear variability. Mean annual maximum and minimum temperatures are $36.6{ }^{\circ} \mathrm{C}$ between May and August and $5.7^{\circ} \mathrm{C}$ between December and January, respectively. The maximum and minimum temperatures registered in outdoors and light-proof buildings during the experiment are shown in Figure 1. Nineteen male Creole goats, 2.5 years (yr) old at the beginning of the experiment, were used. The characteristics of the males of this population have been reported previously [6]. Briefly, these males, called Criollo, are derived from the Spanish Granadina, Murciana and Malagueña breeds imported during the 16th century. During the last $40 \mathrm{yr}$, some cross-breeding with Alpine, Saanen and Anglo-Nubian breeds has been performed. Most animals graze on native pasture without supplementary feeding every day between $0800-1000 \mathrm{~h}$ and 1700-1900 h. At night, they remain in an open shed. Under this management system, the body weight of adult males is about $45 \mathrm{~kg}$. During the present study, males were given ad libitum access to alfalfa hay (18\% $\mathrm{CP}$ ), water and mineral blocks, and $200 \mathrm{~g}$ of commercial concentrate $(14 \% \mathrm{CP}$; $1.7 \mathrm{Mcal} \cdot \mathrm{kg}^{-1}$ ).

\subsection{Photoperiod treatments}

The bucks of the control group $(n=7)$ remained in a $5 \times 7 \mathrm{~m}$ open shed under natural daylength and ambient temperature throughout the experiment. One wk before the onset of the study, the males of the experimental groups $(n=6$ each) were 


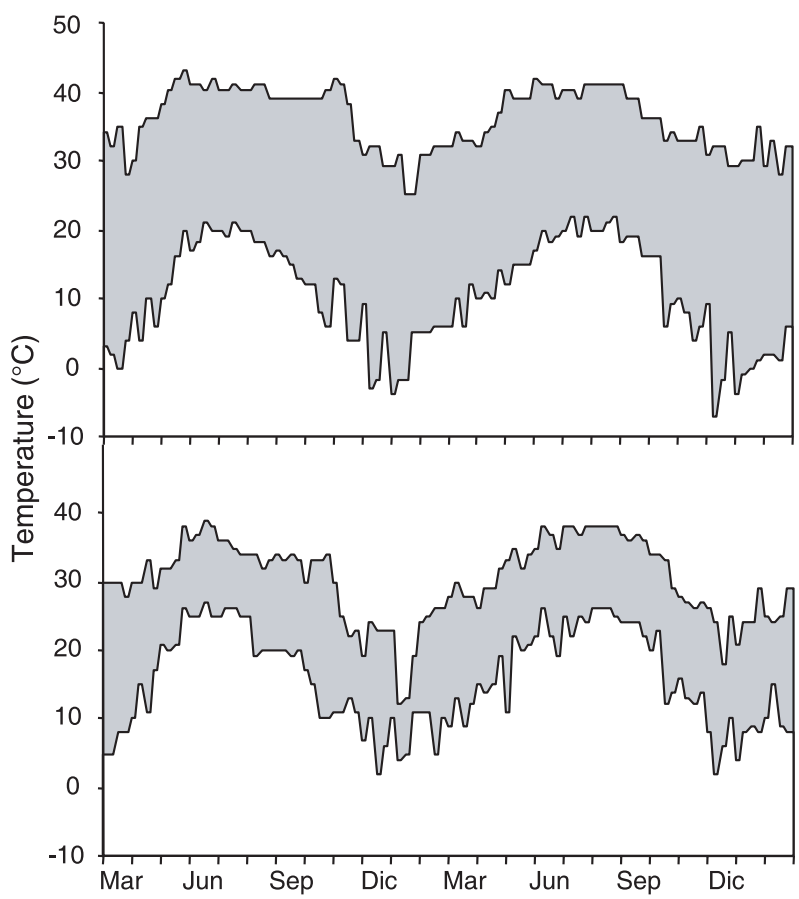

Figure 1. Mean maximum and minimum temperatures throughout the experimental period in open shed (top) and light-proof buildings (bottom). Temperatures were recorded once a week.

placed in two $6 \times 5 \mathrm{~m}$ light-proof sheds and were exposed for 2 consecutive years to alternations of 3 months (mo) of long days (LD: $14 \mathrm{~h}$ of light/day; lights-on: $0700 \mathrm{~h}$, lights-off: $2100 \mathrm{~h}$ ) and 3 mo of short days (SD:10 h of light/day; lights-on: $0700 \mathrm{~h}$, lights-off: $1700 \mathrm{~h}$ ). The photoperiodic treatment started on March 1st and was shifted by 3 mo between the 2 experimental groups (group 1, first exposed to long days, group 2, to short days) in order to control for the effect of non-photoperiodic environmental changes. In each room, light was provided by 8 fluorescent tubes giving a light intensity of at least $300 \mathrm{~lx}$ measured laterally to the eyes of the animals. Photoperiod was regulated by an electric clock. Temperature was not artificially controlled in light-proof buildings and annual changes in the rooms and open shed are shown in Figure 1.

\subsection{Measurements and blood samplings}

Body and testicular weights were measured every two wk throughout the experiment. Testicular weight was determined by comparative palpation of the left testis with an orchidometer [12], always performed by the same operator. This orchidometer was made of a set of wooden testis-shaped beads ranging from 50 to $350 \mathrm{~g}$ in $25-\mathrm{g}$ increments. Plasma testosterone concentrations were determined in samples obtained weekly by jugular venepuncture at $0900 \mathrm{~h}$ throughout the experiment. Plasma was obtained after centrifugation at $2500 \mathrm{~g}$ for $20 \mathrm{~min}$, and stored at $-15{ }^{\circ} \mathrm{C}$ until hormone determination. Testosterone was measured by radioimmunoassay in duplicate, in $50 \mu \mathrm{L}$ plasma samples, as described by Garnier et al. [13]. Sensitivity was $0.1 \mathrm{ng} \cdot \mathrm{mL}^{-1}$. The 
intra-assay and inter-assay coefficient of variation were 8.3 and $10.3 \%$, respectively.

\subsection{Data analysis}

The data obtained during the first three months of the study (March to May) were excluded from the statistical analysis because it was considered as being the necessary period of adaptation of the animals to the sheds and treatments; these data are, however, displayed in the figures. Changes in body and testicular weights and testosterone concentration in the 3 groups were analysed by a two-way ANOVA with repeated measures (time as the within factor and group as the between factor). Thereafter, the same analysis bearing only on the two experimental groups was performed, either on the raw data or after a 3-mo translation of the data of one experimental group (in order to bring the photoperiodic schedules of the two groups in phase using the first short to long day shift as a common reference). In addition, the changes in body weight (BW) during each long-day or shortday period were calculated and, for each animal, average long-day and short-day changes were obtained and analyzed by a two-way ANOVA with repeated measures (photoperiod as the within factor and group as the between factor). The same analysis was performed on the average long-day and short-day testosterone concentrations and testicular weight. Analyses were computed using SuperANOVA and StatView (Abacus Concepts Inc., Berkeley, CA) and the results are expressed as mean \pm SEM.

\section{RESULTS}

\subsection{Body weight}

The BW of the control group varied with the time of the experiment $(P<0.0001)$. In this group, BW increased between January and May and decreased between June and November (Fig. 2, top). The experimental groups also displayed strong changes in body weight throughout the experiment $(P<$ 0.0001 ) but the timing of these changes was profoundly modified by the photoperiodic treatment (interaction time of the experiment*group, $P<0.0001$ for both experimental groups vs. controls). In both experimental groups, BW increased gradually during each 3 mo long-day exposure (10.1 \pm 1.9 and $9.0 \pm 0.9 \mathrm{~kg}$ on average in groups 1 and 2, respectively). Conversely, it decreased gradually during short-day exposure $(-9.8 \pm$ 1.2 and $-9.4 \pm 0.7 \mathrm{~kg}$ on average in groups 1 and 2, respectively; Fig. 2, middle and bottom). The effect of the photoperiodic treatment was not different between the groups as demonstrated by the absence of the time* group interaction when the data were analysed using the first short to long day shift as a common reference.

\subsection{Testicular weight}

Marked changes in testicular weight were observed in the control group throughout the experiment $(P<0.0001)$. In both experimental years, testicular weight began to increase in March and reached maximal values in June. Afterwards, the testis size decreased gradually and minimal values were observed from December to February (Fig. 3, top). After 3 mo of adaptation to the treatment, testicular weight displayed a large decrease in both groups during the following 6 mo $(-30.8 \pm 6.2$ and $-40.0 \pm 7.5 \mathrm{~g}$ between June 1st and December 1st in group 1 and 2, respectively). Thereafter (last 15 mo of the study), in both experimental groups, testicular weight varied over time $(P<0.01)$, and the interaction time of the experiment*group indicated that these changes were modified by the photoperiodic treatment $(P<0.01$ between the two experimental groups; Fig. 3, middle and top). The effect of the photoperiodic treatment was not different between the groups as demonstrated by the absence of the time* group interaction when the data were analysed using the shift from long to short days as a common reference. This effect of photoperiod 


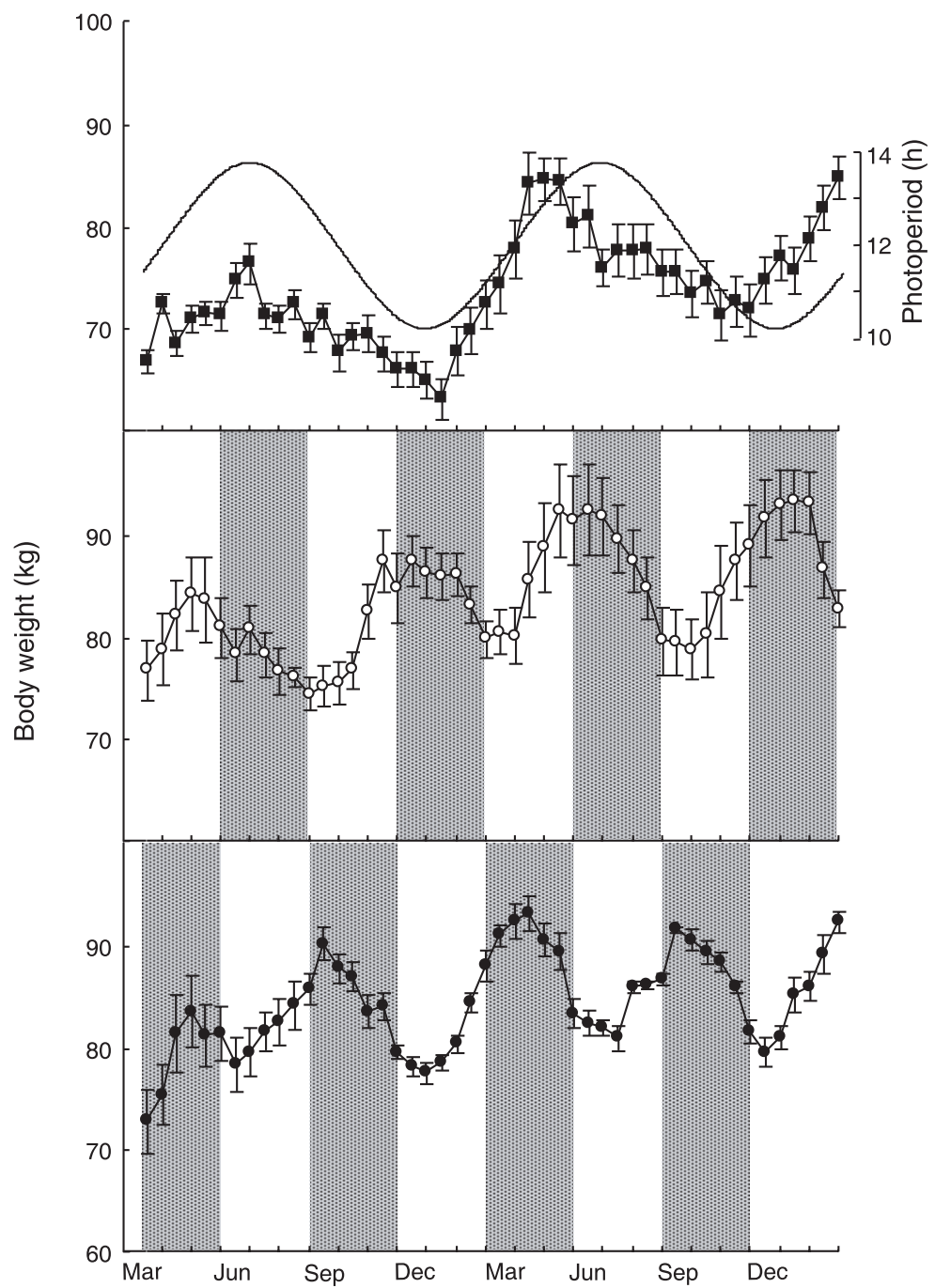

Figure 2. Changes (mean \pm SEM) in live weight in three groups of male Creole goats subjected either to natural changes in daylength (top) or to alternations between three months of long days and three months of short days (middle and bottom). Photoperiodic treatment was shifted by three months to control the effects of non-photoperiodic environmental changes: one group was first exposed to long days (middle) and the other one to short days (bottom). Body weight was measured twice a month. In the top panel, natural changes in photoperiod are represented by a sinewave and, in the bottom panels, the grey areas indicate the months when the experimental animals were exposed to short days.

was further demonstrated by the observation of higher testicular weight during exposure to short days than to long days in both groups (the SD-LD difference was
$13.2 \pm 2.4 \mathrm{~g}$ and $5.7 \pm 2.7 \mathrm{~g}$ in group 1 and 2 , respectively; the effect of the photoperiod: $P<0.001$, interaction group* ${ }^{*}$ hotoperiod: $P>0.05$ ). 


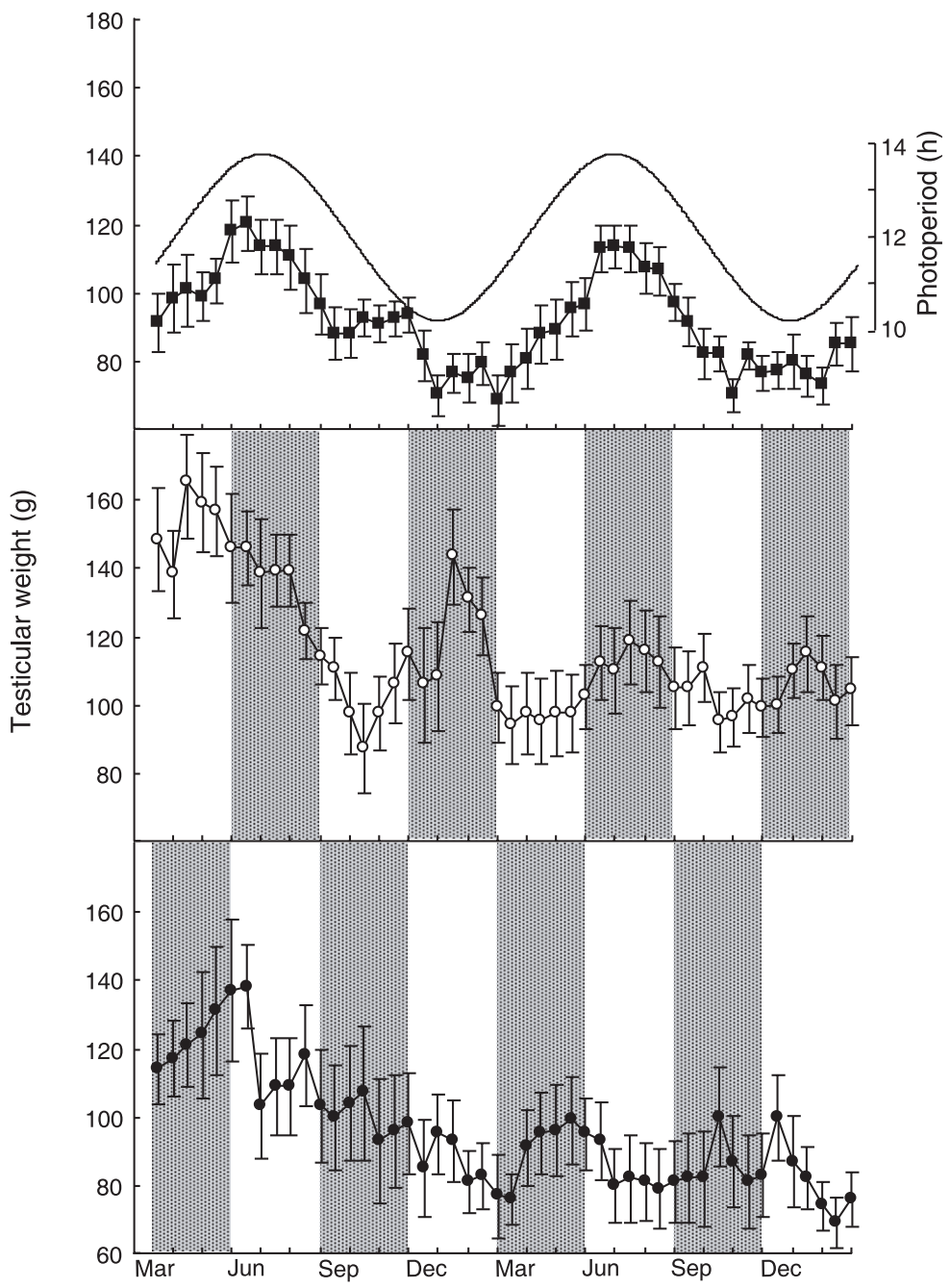

Figure 3. Changes (mean \pm SEM) in testicular weight in the three groups of male Creole goats subjected either to natural changes in daylength (top) or to alternations between three months of long days and three months of short days (middle and bottom). Photoperiodic treatment was shifted by three months to control the effects of non-photoperiodic environmental changes: one group was first exposed to long days (middle) and the other one to short days (bottom). Testicular weight was measured twice a month. In the top panel, natural changes in photoperiod are represented by a sinewave and, in the bottom panels, the grey areas indicate the months when the experimental animals were exposed to short days.

\subsection{Patterns of testosterone secretion}

In the control group, plasma testosterone concentrations varied with the time of the experiment $(P<0.0001)$. Testosterone lev- els started to increase in May-June to reach a plateau in July and started to decrease in November-December to reach a baseline at the end of December (Fig. 4, top). The experimental groups also displayed strong 


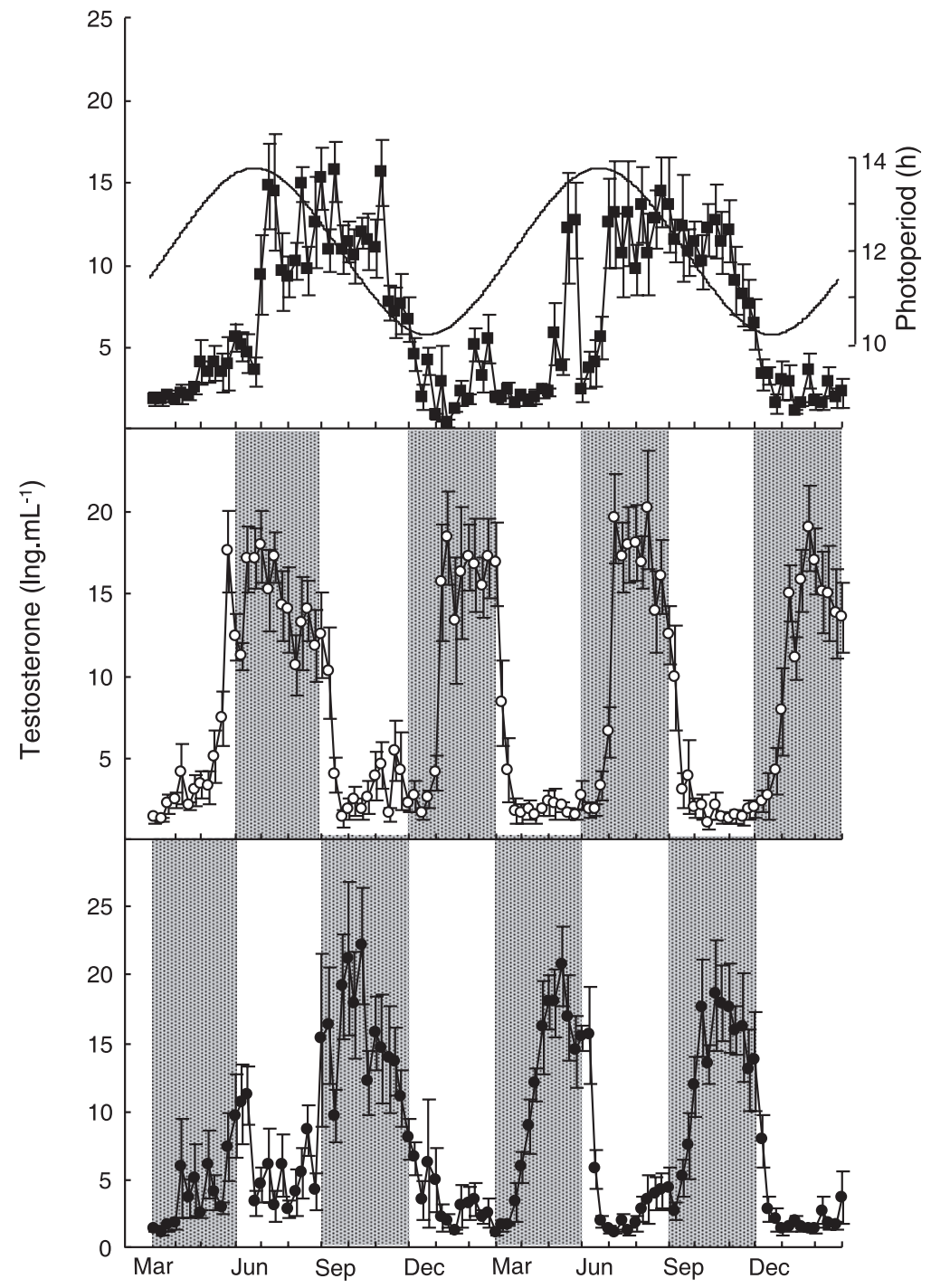

Figure 4. Changes (mean \pm SEM) in plasma testosterone concentrations in the three groups of male Creole goats subjected either to natural changes in daylength (top) or to alternations between three months of long days and three months of short days (middle and bottom). Photoperiodic treatment was shifted by three months to control the effects of non-photoperiodic environmental changes: one group was first exposed to long days (middle) and the other one to short days (bottom). Blood samples were taken once a week. In the top panel, natural changes in photoperiod are represented by a sinewave and, in the bottom panels, the grey areas indicate the months when the experimental animals were exposed to short days.

changes in testosterone concentrations throughout the experiment $(P<0.001)$ but the timing of these changes was profoundly

modified by the photoperiodic treatment (interaction time of the experiment*group, $P<0.001$ for both experimental groups vs. 
the controls). In both experimental groups, testosterone secretion increased abruptly on average $4 \mathrm{wk}$ after the shift from long to short days and decreased abruptly around the time of the shift from short to long days (Fig. 4, middle and bottom). As a result, in group 1, mean testosterone concentrations were higher in short $\left(13.0 \pm 3.6 \mathrm{ng} \cdot \mathrm{mL}^{-1}\right)$ than in long days $\left(2.8 \pm 0.6 \mathrm{ng} \cdot \mathrm{mL}^{-1}\right)$. The same phenomenon occurred in group 2 $\left(11.2 \pm 1.6\right.$ and $3.5 \pm 0.5 \mathrm{ng} \cdot \mathrm{mL}^{-1}$, respectively). The effect of the photoperiodic treatment was not different between the groups as demonstrated by the absence of the time of experiment*group interaction when the data were analysed using the shift from long to short days as a common reference.

\section{DISCUSSION}

We previously showed that male Creole goats adapted to a subtropical environment fed ad libitum, displayed large seasonal variations in their sexual activity, suggesting that an environmental factor other than food availability, is involved in the seasonal changes of the reproductive activity of these animals [6]. The present data extend this conclusion by showing that photoperiod is a major environmental factor of regulation of testosterone secretion over the year. Indeed, changes in photoperiod with an amplitude normally encountered at this latitude, impose their period to changes in testosterone secretion without any evidence for an interaction with temperature changes, despite the occurrence of high temperatures in lightproof buildings in the spring and summer. The same conclusion applies to seasonal changes in body weight and testicular weight, although an overall reduction caused by the experimental conditions was observed for this latter parameter. Together, these data indicate that photoperiod may play a crucial role in timing the physiology of goats with respect to the seasonal fluctuations of the subtropical environment.
The effect of photoperiod on testosterone secretion was very consistent. Regardless of the experimental groups, testosterone secretion increased after about one month of exposure to short days and decreased prior to the shift to long days, probably due to refractoriness to stimulatory short days [14]. In addition, the amplitude of the variations was at least as high as that found in control animals. Concerning testicular weight, although the amplitude of the variations was severely reduced following the initial decrease during the first 9 months of the study, which prevented a precise analysis of the timing of the response, testicular weight was consistently higher during the short days than during the long days. This indicates that photoperiod is a potent factor that controls testosterone secretion and regulates to a lesser extent testicular weight in these animals. Because the temperature reaches high values in this environment in the spring and summer, this factor may play some role in the timing of reproduction. For this reason, we included two groups receiving the photoperiodic treatment out of phase, i.e. the relationship between photoperiodic and temperature variations was different in the two groups. Despite this, the characteristics of the response to photoperiod were not different between the groups indicating that the temperature did not play an important role, if any, in the timing of reproductive activity. Since variations in temperature (this paper) and food availability [6] do not play an important role in this regard, we therefore propose that in this subtropical environment, photoperiod is the main cue that determines the timing of the breeding season over the year.

The decrease in testicular weight observed in both experimental groups during the first 9 months of the study was unexpected. This phenomenon occurred independently of prevailing photoperiod and could have resulted from several causes. Firstly, chronic overheating of the testis can cause a reduction in testicular size without a long-term effect on testosterone secretion [15]. In our study, 
the dramatic reduction in testicular weight observed in both light-treated groups, could be due to the exposure to a progressive increase in temperature recorded from the beginning of the study in March in the light proof building (up to $39^{\circ} \mathrm{C}$ with a reduced daily amplitude, Fig. 1). A stress effect consequential to being located in a novel environment could also have participated to this effect. However, overheating and stress are unlikely the only causes of this phenomenon because the effects were not uniform across treatments despite similar environmental conditions, sub-tropically adapted goats would be able to withstand daily maxima close to $40{ }^{\circ} \mathrm{C}$ and finally changes in body weight (and by inference, voluntary feed intake) were not affected. Secondly, several studies in subtropical goats and sheep have shown that testicular weight is influenced by live weight [16], with seasonal changes lagging behind changes in live weight. In a previous study [6], a lag time of 6 weeks was found between changes in body weight and testicular weight in our conditions; this was confirmed in the control animals of this study. Accordingly, it was proposed that annual changes in testicular weight in subtropical adapted breeds have two components: the initial increase in the late winter would be driven by an increase in body weight, thereafter photoperiod would stimulate LH secretion resulting in increased testosterone secretion and in a further increase in testicular weight $[3,6,17]$. In light-treated groups, the acceleration of the photoperiodic changes caused live weight to be stimulated by long days and, in contrast, testosterone secretion, an index of LH secretion, to be inhibited by long days. The two components of the changes in testicular weight may thus be conflicting and this would explain the reduced effect of photoperiod on testicular weight. Regardless of the reason for this reduced effect of photoperiod on testicular weight, the males of both light treated groups responded to changes in daylength. Testicular weight was higher during short than long days although the amplitude of the variations was reduced compared to the outdoor controls.

In the control group exposed to natural variations in photoperiod and temperature, plasma testosterone concentrations and testicular weight displayed large seasonal variations throughout the 2-yr study that were consistent with those reported previously in males of the same breed in the same conditions $[6,9]$. Testicular volume started to increase in March to reach a maximum in June and testosterone secretion started to increase in May and remained elevated until November. The breeding season occurs therefore much earlier than in breeds adapted to higher latitudes; for instance, in Alpine bucks the breeding season begins in September at $45^{\circ} \mathrm{N}$ [18]. In the photoperiod treated groups, these seasonal changes were dramatically modified: testosterone secretion increased rapidly after about 4 weeks of exposure to short days and decreased within a few days after the beginning of exposure to long days and testicular weight was higher in short days than in long days. This response to photoperiod is very similar to that found in breeds of goats and sheep adapted to higher latitudes. For instance, Alpine male goats exposed to alternations of 2 mo of $16 \mathrm{~L}: 8 \mathrm{D}$ and 2 mo of $8 \mathrm{~L}: 16 \mathrm{D}$, display a strong increase in testosterone secretion after 4 wk of short days and a decrease after 2 wk of long days [19]. Similarly, Soay rams exposed to alternations of 16 weeks of $16 \mathrm{~L}: 8 \mathrm{D}$ and $8 \mathrm{~L}: 16 \mathrm{D}$ display increases in testosterone secretion after 1 to $8 \mathrm{wk}$ of short days and decreases 1 to $2 \mathrm{wk}$ after long days [20]. Our data therefore indicate that photoperiod is the main factor that regulates the breeding season but they are also very interesting because they show that the timing of the breeding season is very different between subtropical and temperate areas. This difference is not due to the amplitude of the changes in photoperiod (reduced in subtropical areas) since using a subtropical photoperiod range did not modify the timing of the response compared to temperate areas. Alternatively, the difference in the timing of the breeding season results from 
the genetics of these animals. This difference is not due to the interpretation of the photoperiod: short and long days exert stimulatory and inhibitory effects, respectively, in both situations with similar timings. This latter observation does not support the hypothesis forwarded by Hafez [21] that reduced seasonality would result from reduced susceptibility to the inhibitory effects of long days in the spring and early summer. The difference between the animals adapted to the two geographical areas therefore most likely lies in the way photoperiod synchronises the endogenous rhythm of reproduction. In temperate areas, it is thought that long days of spring time the onset of the breeding season by resetting this endogenous rhythm [22]. In subtropical areas, long days could play the same role. Indeed, we have recently shown that the onset of the breeding season assessed through testosterone secretion was advanced in male goats exposed to constant long days (16 h of light $\cdot \mathrm{d}^{-1}$ ) from November. In treated animals, plasma testosterone concentrations started to increase in February, while this increase occurred in May in male goats under natural photoperiodic changes (Flores JA, Poindron P, Malpaux B, Delgadillo JA, unpublished data). We therefore propose that in animals adapted to subtropical conditions, long days perceived in the spring are critical to reset the endogenous rhythm, but this occurs with a shorter lag time between the perception of the signal and the expression of the response assessed by the onset of the breeding season (i.e. about 3 months shorter when comparing Creole to Alpine bucks). As a consequence, the breeding season would start earlier in the year. This would suggest that in these animals, natural selection would have operated, not through direct response to photoperiod but rather by modifying the characteristics of entrainment of the endogenous rhythm.

The results of the present study allow us to conclude that local male goats from subtropical Mexico are sensitive to photoperiodic changes, and suggest that the daylength is an important environmental factor that controls the timing of sexual activity in this environment. Although photoperiod plays this important role in both the subtropical and temperate environments and the timing of the photoperiodic response of animals adapted to each environment is similar, the male breeding season begins earlier in the subtropics which suggests that this adaptation may have occurred through changes in the entrainment of the endogenous circannual rhythm of reproduction by photoperiod. It will be of interest to test whether similar differences are also found in the female.

\section{ACKNOWLEDGEMENTS}

This work was supported in part by the ECOS-ANUIES, CONACyT, SEP exchange program between Mexico and France (M02A04). María Elena Cortez was supported by a CONACyT scholarship. The authors thank the Assay Laboratory of the Station de Physiologie de la Reproduction for carrying out the radioimmunoassays; Ms. Agnès Daveau for technical assistance; Ms. Dolores López for her excellent secretarial assistance; and the two anonymous referees for useful and constructive comments.

\section{REFERENCES}

[1] Walkden-Brown SW, Restall BJ, Scaramuzzi RJ, Martin GB, Blackberry MA. Seasonality in male Australian cashmere goats: long term effects of castration and testosterone or oestradiol treatment on changes in LH, FSH and prolactin concentrations, and body growth. Small Rumin Res 1997, 26: 239-252.

[2] Pérez Clariget R, Forsberg M, RodríguezMartínez H. Seasonal variation in live weight, testes size, testosterone, LH secretion, melatonin and thyroxine in Merino and Corridale rams in a subtropical climate. Acta Vet Scand 1998, 39: 35-47.

[3] Walkden-Brown SW, Restall BJ, Norton BW, Scaramuzzi RJ, Martin GB. Effect of nutrition on seasonal patterns of LH, FSH and testosterone concentration, testicular mass, sebaceous gland volume and odour in Australian cashmere goats. J Reprod Fertil 1994, 102: 351360 . 
[4] Martin GB, Hötzel MJ, Blache D, WalkdenBrown ST, Blackberry MA, Boukhliq R, Fisher JS, Miller DW. Determinants of the annual pattern of reproduction in mature male Merino and Suffolk sheep: modification of responses to photoperiod by an annual cycle in food supply. Reprod Fertil Dev 2002, 14: $165-175$

[5] Sáenz-Escárcega P, Hoyos LG, Salinas H, Martínez M, Espinoza JJ, Guerrero A, Contreras E. Establecimiento de módulos caprinos con productores cooperantes. In: INIFAP-CIID (Ed), Reunión de evaluación de módulos caprinos en la comarca Lagunera, México, Proc 1st Reunión Informativa, 1991, p 24-34.

[6] Delgadillo JA, Canedo GA, Chemineau P, Guillaume D, Malpaux B. Evidence for an annual reproductive rhythm independent of food availability in male creole goats in subtropical northern Mexico. Theriogenology 1999, 52: 727-737.

[7] Flores JA, Véliz FG, Pérez-Villanueva JA, Martínez de la Escalera G, Chemineau P, Poindron P, Malpaux B, Delgadillo JA. Male reproductive condition is the limiting factor of efficiency in the male effect during seasonal anestrus in female goats. Biol Reprod 2000, 62: $1409-1414$

[8] Delgadillo JA, Carrillo E, Morán J, Duarte G, Chemineau P, Malpaux B. Induction of sexual activity of male creole goats in subtropical northern Mexico using long days and melatonin. J Anim Sci 2001, 79: 2245-2252.

[9] Delgadillo JA, Flores JA, Véliz FG, Hernández HF, Duarte G, Vielma J, Poindron P, Chemineau $\mathrm{P}$, Malpaux B. Induction of sexual activity in lactating anovulatory female goats using male goats treated only with artificially long days. J Anim Sci 2002, 80: 2780-2786.

[10] Staples L, McPhee S, Reeve J, Williams AH. Practical applications for controlled release melatonin implants in sheep. In: Foldes A, Reiter RJ (Ed.), Advances in Pineal Research, John Libbey \& Co Ltd, London, 1991, p 199 208.

[11] Chemineau P, Malpaux B, Delgadillo JA, Guérin Y, Ravault JP, Thimonier J, Pelletier J. Control of sheep and goat reproduction: use of light and melatonin. Anim Reprod Sci 1992, 30: 157-184.
[12] Oldham CM, Adams NR, Gherardi PB, Lindsay DR, McKintosh JB. The influence of level of feed intake on sperm-producing capacity of testicular tissue in the ram. Aust J Agric Res 1978, 29: 173-179.

[13] Garnier DH, Cotta Y, Terqui M. Androgen radioimmunoassay in the ram: results of direct plasma testosterone and dehydroepiandrosterone measurement and physiological evaluation. Ann Biol Anim Biochim Biophys 1978, 18: $265-281$.

[14] Almeida OFX, Lincoln GA. Reproductive photorefractoriness in rams and accompanying changes in the patterns of melatonin and prolactin secretion. Biol Reprod 1984, 30: 143-158.

[15] Setchell BP. Heat and the testis. J Reprod Fertil 1998, 114: 179-194.

[16] Martin GB, Walkden-Brown SW. Nutritional influences on reproduction in mature male sheep and goats. J Reprod Fertil Suppl 1995, 49: 437-449.

[17] Hotzel MJ, Walkden-Brown SW, Fisher JS, Martin GB. Determinants of the annual pattern of reproduction in mature male Merino and Suffolk sheeep: responses to a nutritional stimulus in the breeding and non-breeding seasons. Reprod Fertil Dev 2003, 15: 1-9.

[18] Delgadillo JA, Leboeuf B, Chemineau P. Decrease in the seasonality of sexual behavior and sperm production in bucks by exposure to short photoperiodic cycles. Theriogenology 1991, 36: 755-770.

[19] Delgadillo JA, Chemineau P. Abolition of the seasonal release of luteinizing hormone and testosterone in Alpine male goats (Capra hircus) by short photoperiodic cycles. J Reprod Fertil 1992, 94: 45-55.

[20] Lincoln GA, Short RV. Seasonal breeding: nature's contraceptive. Rec Prog Horm Res 1980, 36: 1-52.

[21] Hafez ESE. Studies on the breeding season and reproduction of the ewe. J Agric Sci 1952, 42: 189-265.

[22] Malpaux B, Robinson JE, Wayne NL, Karsch FJ. Regulation of the onset of the breeding season of the ewe: importance of long days and of an endogenous reproductive rhythm. J Endocrinol 1989, 122: 269-278. 